\title{
Evaluating Wealth Management Centers in the Pearl River Delta by Using Principal Component Analysis
}

\author{
Weijun Xu, Shaoying Huang and Zhiqiang Wang* \\ School of Business Administration, South China University of Technology, \\ Guangzhou, China \\ *corresponding author: zhiqiangw@gmail.com
}

\begin{abstract}
Because of the rapid development and wealth accumulation in the Pearl River Delta (PRD), most of the cities in this area are motivated to establish wealth management centers (WMCs). We create an evaluation index system for assessing the development level of WMCs in cities in the PRD; we develop this system by selecting 20 indicators including gross regional production (GDP). Subsequently, we use panel data from 2010 to 2013 of nine cities in the PRD to evaluate the financial competitiveness of each of these cities through principal component analysis (PCA); we further analyze the pioneering roles of Guangzhou and Shenzhen in establishing WMCs in the PRD. The numerical analysis results reveal that Shenzhen and Guangzhou rank first and second, respectively, regarding financial competitiveness in the PRD, indicating that the two cities play a leading role in the establishment of WMCs in the PRD.
\end{abstract}

Keywords: Wealth management; financial competitiveness; principal component analysis; panel data

\section{Introduction}

Wealth management has been an emerging business area in recent years, and international financial institutions have strongly emphasized developing this area. It is one of the most profitable areas in the financial services industry. Since the implementation of China's reform and opening-up policies in 1978, China's national wealth has accumulated swiftly, and the total number of high-net-worth individuals has increased rapidly. Consequently, demand for wealth management has become an urgent problem in the economic development of China. The PRD is strategically located because it is adjacent to Hong Kong and Macao. Moreover, because it serves as the southern gateway to the opening-up policy, it is the main area of global economic activity and a vital economic region that provides an essential foundation for creating a wealth management center (WMC). According to statistics from the China and Provinces Statistical Yearbook for 2009-2013, the two core cities in the PRD, namely Guangzhou and Shenzhen, ranked third and fourth, respectively, in the national economy. In addition, other cities in the PRD such as Foshan, Dongguan, and Zhuhai, are developing rapidly, and the financial industry in these cities is well-established. The "Pearl River Delta Region Reform and Development Plan (2008-2020)" was proposed to support Guangzhou and Shenzhen to construct a regional financial center and create a multilevel capital market system. This plan also proposes establishing a highly diversified, relatively precise comprehensive financial service system. This plan provides crucial policy support for constructing a WMC in the PRD. In recent years, financial institutions have become involved in the wealth management business and have established wealth management departments. Furthermore, foreign banks have entered the domestic wealth management market. Several large cities have also attempted to construct their own WMCs. Therefore, creating an index system for evaluating the development level of WMCs in the PRD is imperative 
to comprehensively evaluate the financial competitiveness of the cities in this area, and such a system has major practical relevance and academic value in the development of the PRD and wealth management theory.

Financial competitiveness serves as an essential basis for establishing WMCs and plays a critical role in evaluating the competitiveness of a nation. The competitiveness of nations has been extensively researched since the early 1980s, and Anderson and Dunnett [1] first studied this topic. The most prominent systems for studying financial competitiveness are the World Competitiveness Report (WCR), which is based on the academic theory of Porter [2], and the Global Financial Centers Index (GFCI). The World Economic Forum and Swiss IMD analyze and report the WCR annually. Porter [2] proposed a methodology called "the National Diamond" and used it to study the competitiveness of 10 selected countries and to develop a plan for each of these countries to enable them to increase their international competitiveness. In 2007, the City of London Corporation published the GFCI, which is the first authoritative index system to professionally rank the major global financial centers. Oral and Chabchoub [3, 4] explained the methodology used in the WCR. They proposed a mathematicalprogramming-based approach to "guess" missing information as well as a mathematicalprogramming-based estimation model to replicate the WCR rankings.

A WMC is a regional financial center, and many studies have evaluated international financial centers [5].Most of these studies have focused on London [6], the European Continent [7], and the Mediterranean. Researchers have emphasized New York, Montreal, and Toronto since World War I. Asian financial centers [8] were investigated in the late 1960s, with the main emphasis being placed on Singapore [9] and Hong Kong [10]. Poon [11] examined the spatial organization and evolution of capital markets in 43 cities and determined that the hierarchical tendencies of capital markets among international financial centers were strengthened, indicating the characteristics of top-tier cities. In addition, other studies have been conducted on regional financial centers $[12,13]$.

In China, scholars are increasingly studying financial centers. Yin et al. [14] pioneered the use of statistical methods to evaluate the financial competitiveness of 15 cities in the Yangtze River Delta. Xiao [15] reviewed the literature on the financial competitiveness of cities and revealed the connotations, relevance, and evaluation indicators of a city's financial competitiveness. Zhang et al. [16] designed an evaluation system to assess the financial competitiveness of cities in China; they used this system to analyze the five central cities of China (Shanghai, Beijing, Shenzhen, Guangzhou, and Tianjin). Cheng and Tang [17] employed PCA to compare and evaluate the financial competitiveness of 11 provincial capital cities in the West. Fang [18] used PCA and Wilson models to study the financial competitiveness of the cities in the PRD and financial radiation. Several other researchers [19-22] have also studied the financial competitiveness of various cities.

According to our literature review, few studies have focused on the financial competitiveness of cities in the PRD, which is a vital and major economic area in China. In addition, PCA-based evaluations incorporating panel data are not extensively used in financial competitiveness assessments. Therefore, in this study, we attempt to create an evaluation system for assessing the financial competitiveness of each city in the PRD and its corresponding WCMs by using PCA and panel data. According to a previous definition of financial competitiveness, we first select various indicators including a city's financial environment and urban finance scale as well as 20 subindicators of urban benefits (Section 2). Subsequently, we determine the financial competitiveness of the cities in the PRD by using PCA and then rank the cities by conducting an empirical analysis (Section 3 ). In addition, further analysis is conducted to determine the status of Guangzhou and Shenzhen in constructing WMCs. Finally, we provide a conclusion and recommendations in Section 4. 


\section{Indicator Selection and Data Collection}

\subsection{Selection of Urban Financial Competitiveness Indicators}

Urban financial competitiveness refers to comprehensive competitiveness regarding the financial industry including the banking, securities, and insurance industries. The GFCI published by the City of London Company Global Financial covers personnel, business environment, market access, infrastructure, and other indicators. It provides an evaluation index system for studying financial competitiveness. Evaluation systems must be established according to the purpose, scientific requirements, system requirements, merit principle, comparability, qualitative requirements, and quantitative requirements of a study. According to previous studies and the status of cities in the PRD, this study investigates urban financial competitiveness on the basis of three major indicators, namely the city financial environment, urban finance scale, and urban benefits and deepening [5]. These indicators have several secondary indicators (Table 1). In the analysis of multivariable problems, excessive variables lead to information overlap, thus increasing the computational load and complexity of the analysis. Therefore, reducing the dimension of multiple variables is necessary. The dimensions of multiple variables can be reduced using several methods, such as PCA, factor analysis (FA), linear discriminant analysis, maximum variance unfolding (MVU), and local preserving projection (LPP). Compared with other methods, PCA has advantages. PCA is a typical linear dimension reduction technique and is easy to understand and convenient to compute. In contrast to several methods such as FA, PCA requires no hypotheses. Moreover, PCA is a global dimension reduction method, whereas LPP and MVU are local dimension reduction approaches. Therefore, we use PCA to establish the evaluation system for assessing WMCs in the PRD.

\subsection{Principal Component Analysis}

The main purpose of PCA is to reduce the dimensionality of a dataset. In this technique, multiple indicators are translated into a few integrated indicators called principal components. Each principal component is a linear combination of the original variables. Each of the principal components is uncorrelated and extracts most of the information from the original variables. The contained information is non-overlapping. The main PCA steps are outlined as follows.

Table 1. Framework of Indicators

\begin{tabular}{l|l}
\hline $\begin{array}{c}\text { Major } \\
\text { indicators }\end{array}$ & \multicolumn{1}{|c}{ Sub-indicators } \\
\hline \multirow{4}{*}{$\begin{array}{l}\text { City } \\
\text { financial } \\
\text { environment }\end{array}$} & $\mathrm{X}_{1}:$ GDP(100 million Yuan) \\
\cline { 2 - 2 } & $\mathrm{X}_{2}:$ Construction costs (Yuan) \\
\cline { 2 - 2 } & $\mathrm{X}_{3}:$ GDP growth rate (\%) \\
\cline { 2 - 2 } & $\mathrm{X}_{4}:$ Per GDP(Yalue-added of the Tertiary Industry(100 million \\
\cline { 2 - 2 } & $\mathrm{X}_{6}:$ Investment in Fixed Assets (100 million Yuan) \\
\cline { 2 - 2 } & $\mathrm{X}_{7}:$ Investment in education (100 million Yuan) \\
\cline { 2 - 2 } & $\mathrm{X}_{8}:$ Foreign Direct Investment (100 million Yuan) \\
\hline \multirow{4}{*}{$\begin{array}{l}\text { Urban } \\
\text { finance } \\
\text { scale }\end{array}$} & $\mathrm{X}_{9}:$ Financial professionals (10 thousand) \\
\cline { 2 - 2 } & $\mathrm{X}_{10}:$ Number of corporate financial institutions \\
\cline { 2 - 2 } & $\mathrm{X}_{11}:$ Year-end deposit balance of all financial institutions \\
\hline
\end{tabular}




\begin{tabular}{|c|c|}
\hline & (100 million Yuan) \\
\hline & $\begin{array}{l}\mathrm{X}_{12} \text { :Year-end balance of loans of all financial institutions } \\
\text { (100 million Yuan) }\end{array}$ \\
\hline & $\mathrm{X}_{13}:$ Deposit proportion $(\%)$ \\
\hline & $\mathrm{X}_{14}:$ Loan proportion $(\%)$ \\
\hline & $\mathrm{X}_{15}:$ Savings Balance (100 million Yuan) \\
\hline & $\mathrm{X}_{16}$ :Budget expenditures (100 million Yuan) \\
\hline \multirow{4}{*}{$\begin{array}{l}\text { Urban } \\
\text { benefits and } \\
\text { deepening }\end{array}$} & $\mathrm{X}_{17}$ :Financial Gross (100 million Yuan) \\
\hline & $\mathrm{X}_{18}$ :Value-added of Financial Gross(100 million Yuan) \\
\hline & $\mathrm{X}_{19}:$ Deposit ratio(\%) \\
\hline & $\mathrm{X}_{20}$ : Finance-related rate $(\%)$ \\
\hline
\end{tabular}

(1) Normalize raw data. Because the dimension of each indicator is inconsistent in raw data, the data must be normalized to a dimensionless format before analysis. Numerous normalization methods are available, and we use the following method:

$$
x_{i j}^{*}=\frac{x_{i j}-x_{j}}{s_{j}}
$$

where $x_{i j}$ represents the value of the $i$ th alternative in the $j$ th subindicator, $x_{i j}{ }^{*}$ represents the normalized alternative $i \in\{1,2, \ldots, n\}, j \in\{1,2, \ldots, p\}, s_{j}$ represents the standard deviation of the $j$ th subindicator, and $x_{j}$ represents the mean of all alternatives in the $j$ th subindicator.

(2) Calculate the covariance matrix/correlation matrix $R$ of matrix $\left[x_{i j}^{*}\right]_{n \times p}$.

(3) Compute the eigenvalue $\lambda_{j}$ and relative eigenvector $\mu_{j}$ of matrix $R$.

(4) Calculate the contribution rate $\lambda_{j} / \sum_{j=1}^{p} \lambda_{j}$ of each principal component and a corresponding load matrix according to the eigenvalues.

(5) Select the first few principal components whose cumulative contribution rate is greater than $85 \%$ or whose eigenvalue is higher than 1 , and explain the significance of the principal components according to the eigenvalueand eigenvector.

\section{Empirical Analysis}

This section presents the procedures involved in establishing the evaluation system employed for assessing the financial competitiveness of cities in the PRD by using PCA and panel data. Panel data refer to multidimensional data that typically involve measurements of financial performance of an establishment over time. Panel data contain observations of multiple phenomena obtained over multiple time periods for the same firms or people. Time series and cross-sectional data are special cases of panel data that are present in only a single dimension (i.e., one panel member or individual for time series data and one time point for cross-sectional data). Conventional PCA entails using cross-sectional data. Incorporating panel data into conventional PCA can increase its robustness. 


\subsection{Data Selection and Data Sources}

Table 2.Structure of Panel Data

\begin{tabular}{c|c|c|c}
\hline $\mathbf{2 0 1 0}(\mathbf{t}=\mathbf{1})$ & $\mathbf{2 0 1 1}(\mathbf{t}=\mathbf{2})$ & $\mathbf{2 0 1 2}(\mathbf{t}=\mathbf{3})$ & $\mathbf{2 0 1 3}(\mathbf{t}=\mathbf{4})$ \\
\hline $\mathbf{X}_{\mathbf{1}}, \mathbf{X}_{\mathbf{2}}, \ldots, \mathbf{X}_{\mathbf{2 0}}$ & $\mathbf{X}_{\mathbf{1}}, \mathbf{X}_{2,}, \ldots, \mathbf{X}_{20}$ & $\mathbf{X}_{\mathbf{1}}, \mathbf{X}_{2}, \ldots, \mathbf{X}_{\mathbf{2 0}}$ & $\mathbf{X}_{\mathbf{1}}, \mathbf{X}_{2,}, \ldots, \mathbf{X}_{20}$ \\
\hline $\mathbf{x}_{\mathbf{1 1}}(\mathbf{1}), \ldots, \mathbf{x}_{\mathbf{1 1}}(20)$ & $\mathrm{x}_{12}(1), \ldots, \mathrm{x}_{12}(20)$ & $\mathrm{x}_{13}(1), \ldots, \mathrm{x}_{13}(20)$ & $\mathrm{x}_{14}(1), \ldots, \mathrm{x}_{14}(20)$ \\
\hline$\cdots$ & $\cdots$ & $\ldots$ & $\cdots$ \\
\hline $\mathrm{x}_{5}(1), \ldots, \mathrm{x}_{51}(20)$ & $\mathrm{x}_{52}(1), \ldots, \mathrm{x}_{52}(20)$ & $\mathrm{x}_{53}(1), \ldots, \mathrm{x}_{53}(20)$ & $\mathrm{x}_{54}(1), \ldots, \mathrm{x}_{54}(20)$ \\
\hline$\cdots$ & $\cdots$ & $\cdots$ & $\cdots$ \\
\hline $\mathrm{x}_{91}(1), \ldots, \mathrm{x}_{91}(19)$ & $\mathrm{x}_{92}(1), \ldots, \mathrm{x}_{92}(20)$ & $\mathrm{x}_{93}(1), \ldots, \mathrm{x}_{93}(20)$ & $\mathrm{x}_{94}(1), \ldots, \mathrm{x}_{94}(20)$ \\
\hline
\end{tabular}

We collect data related to the 20 subindicators of nine cities in the PRD, namely Guangzhou, Shenzhen, Zhuhai, Foshan, Huizhou, Dongguan, Zhongshan, Jiangmen, and Zhaoqing, from 2010 to 2013. Subsequently, we establish the evaluation system for quantifying and assessing the financial competitiveness of the cities in the PRD. This system can help us and the government to understand the financial development level of the PRD and can provide a theoretical basis for establishing WMCs in the PRD. The data are mainly collected from the "Guangdong Province Statistical Yearbook" from 2011 to 2014. Therefore, we derive 20 indicators presented in the form of panel data. Table 2 shows the structure of the panel data.

\subsection{Data Processing}

Few studies have combined PCA with panel data. To combine these two methods, we execute the following procedure. First, we apply PCA to each cross-sectional dataset, namely the data for 2010, 2011, 2012, and 2013. Subsequently, we derive the overall financial competitiveness score of each of the nine cities for each year. Finally, we aggregate the comprehensive scores for each year to obtain the overall financial competitiveness of the PRD.

We apply PCA to the data collected in 2010 to assess the financial competitiveness of the nine cities in the PRD for this year. SPSS software is used to analyze the data of 2010 for deriving the corresponding principal components. Table 3 displays the eigenvalues and contribution rates of the principal components associated with the financial competitiveness of the cities in the PRD for the year 2010.

Table 3. Total Variance Explained for 2010

\begin{tabular}{|c|c|c|c|c|c|c|}
\hline \multirow[b]{2}{*}{ Component } & \multicolumn{3}{|c|}{ Initial Eigenvalues } & \multicolumn{3}{|c|}{\begin{tabular}{|l} 
Extraction \\
Loadings
\end{tabular}} \\
\hline & Total & $\left|\begin{array}{ll}\% & \text { of } \\
\text { Variance } & \end{array}\right|$ & cumulative $\%$ & Total & $\left|\begin{array}{ll}\% & \text { of } \\
\text { Variance } & \end{array}\right|$ & cumulative $\%$ \\
\hline 1 & 16.176 & 80.879 & 80.879 & 16.176 & 80.879 & \begin{tabular}{|l|}
80.879 \\
\end{tabular} \\
\hline 2 & 1.511 & 7.555 & 88.434 & 1.511 & 7.555 & 88.434 \\
\hline 3 & 1.242 & 6.210 & 94.644 & 1.242 & 6.210 & 94.644 \\
\hline 4 & .508 & 2.539 & 97.183 & & & \\
\hline 5 & .296 & 1.480 & 98.663 & & & \\
\hline 6 & .160 & .801 & 99.465 & & & \\
\hline$\ldots$ & $\ldots$ & $\ldots$ & $\ldots$ & & & \\
\hline 20 & $\begin{array}{c}-8.803 \mathrm{E}- \\
16\end{array}$ & $-4.402 \mathrm{E}-15$ & 100.000 & & & \\
\hline
\end{tabular}

Table 3 demonstrates that the eigenvalues of the first three components are greater 
than 1 , and the cumulative contribution rate is $94.644 \%$, which is higher than the critical value (i.e., 85\%). Therefore, the first three components are extracted as the principal components. According to the output communalities, the first three principal components extract more than $90 \%$ of the information of 15 original indicators and more than $83 \%$ of the information of 19 indicators. The average extraction rate is $94.65 \%$, indicating that extraction of indicators is very effective. The component matrix is provided in Table 4.

The factor loading matrix demonstrates the following results: (1) Principal component F1 has high loadings in all indicators except for the GDP growth rate. Because F1 assesses most of these indicators, it represents the total level of financial factors. (2) Principal component F2 exhibits high positive loadings in the GDP growth rate, number of corporate financial institutions, financial gross product, and deposit ratio. However, it has high negative loadings in investment in fixed assets, investment in education, and foreign direct investment. Because this principal component assesses assets allocated to financial intermediation and financial output, it represents the external financial factors. (3) Principal component F3 has high loadings in the GDP growth rate and finance-related rate, representing the internal financial factors. Therefore, we can express the formula of the three principal components as follows:

$$
\left\{\begin{array}{l}
F_{1}=\left(0.975 x_{1}+0.892 x_{2}+\cdots+0.839 x_{20}\right) \times \sqrt{16.176} \\
F_{2}=\left(-0.151 x_{1}+0.286 x_{2}+\cdots+0.233 x_{20}\right) \times \sqrt{1.511} \\
F_{3}=\left(0.13 x_{1}-0.325 x_{2}+\cdots-0.406 x_{20}\right) \times \sqrt{1.242}
\end{array}\right.
$$

We aggregate the product of the three principal components and their respective contribution rates as the weight vector. Next, we divide the aggregation result by the cumulative contribution rate to derive the comprehensive component $\mathrm{F}$, as displayed in the following formula:

$$
F=A X=\sum_{i=1}^{n} a_{i} x_{i}=\left(\mathrm{F}_{1} \times 80.879 \%+\mathrm{F}_{2} \times 7.555 \%+\mathrm{F}_{3} \times 6.21 \%\right) \div 94.644 \%
$$

where $A$ is the coefficient matrix and $X$ is the normalized data. Hence, according to formulas (2) and (3), we can compute each primary component's score and the overall component score for the year 2010. A positive score indicates that the alternative's financial competitiveness is higher than the average. By contrast, a negative score indicates that the alternative's financial competitiveness is lower than the average. Similarly, we can calculate the comprehensive component scores of the nine cities for 2011, 2012, and 2013 (Table 5). The average extraction rates for2011, 2012, and 2013 are $94.035 \%, 88.11 \%, 95.08 \%$, respectively. The cumulative contribution rates of the extracted components for 2011, 2012, and 2013 are $94.036 \%, 88.103 \%$, and $95.066 \%$, respectively. These data reveal the effectiveness of the extracted components.

The overall score of the competitiveness of the cities in the PRD can be derived by aggregating the principal component scores and comprehensive scores (Table 5) evaluated over the 3-year period. This aggregation can be conducted using two methods: The first method entails executing a weighted aggregation by using the effectiveness degree of data for the 3 years as the weight vector. The second method involves calculating the arithmetic mean of the data for the 3years. In this study, we adopt the second method and thus derive the final financial competitiveness and ranking of the cities in the PRD (Table 6). 
Table 4. Component Matrix

\begin{tabular}{c|c|c|c|c|c|c|c}
\hline & \multicolumn{3}{|c|}{ Component } & & \multicolumn{3}{c}{ Component } \\
\cline { 2 - 3 } \cline { 7 - 8 } & 1 & 2 & 3 & & 1 & 2 & 3 \\
\hline $\mathrm{X} 1$ & 0.975 & -0.151 & 0.130 & $\mathrm{X} 11$ & 0.991 & -0.066 & 0.088 \\
\hline $\mathrm{X} 2$ & 0.892 & 0.286 & -0.325 & $\mathrm{X} 12$ & 0.993 & 0.026 & 0.076 \\
\hline $\mathrm{X} 3$ & -0.487 & 0.372 & 0.721 & $\mathrm{X} 13$ & 0.991 & -0.066 & 0.088 \\
\hline $\mathrm{X} 4$ & 0.806 & -0.052 & -0.346 & $\mathrm{X} 14$ & 0.993 & 0.026 & 0.076 \\
\hline $\mathrm{X} 5$ & 0.970 & -0.175 & 0.133 & $\mathrm{X} 15$ & 0.953 & -0.261 & 0.138 \\
\hline $\mathrm{X} 6$ & 0.882 & -0.330 & 0.316 & $\mathrm{X} 16$ & 0.984 & 0.160 & 0.037 \\
\hline $\mathrm{X} 7$ & 0.831 & -0.374 & 0.277 & $\mathrm{X} 17$ & 0.934 & 0.319 & -0.055 \\
\hline $\mathrm{X} 8$ & 0.664 & -0.613 & -0.119 & $\mathrm{X} 18$ & 0.956 & 0.264 & -0.014 \\
\hline $\mathrm{X} 9$ & 0.963 & 0.232 & -0.052 & $\mathrm{X} 19$ & 0.839 & 0.351 & 0.233 \\
\hline $\mathrm{X} 10$ & 0.867 & 0.393 & 0.002 & $\mathrm{X} 20$ & 0.839 & 0.066 & -0.406 \\
\hline
\end{tabular}

Table 5. Financial Competitiveness Scores of the Nine Cities in the PRD for 2010, 2011, 2012, and 2013

\begin{tabular}{|c|c|c|c|c|c|c|c|c|c|c|c|c|c|c|}
\hline \multicolumn{4}{|c|}{2010} & \multicolumn{4}{|c|}{2011} & \multicolumn{3}{|c|}{2012} & \multicolumn{4}{|c|}{2013} \\
\hline F1 & $\mathrm{F} 2$ & F3 & $\mathrm{F}$ & F1 & F2 & F3 & F & F1 & $\mathrm{F} 2$ & $\mathrm{~F}$ & F1 & F2 & F3 & F \\
\hline 102.9087 & -2.58719 & 1.246719 & 87.81694 & 97.94603 & -2.6409 & 1.804502 & 83.13042 & 84.75878 & 0.173997 & 73.98971 & 99.66398 & 5.12527 & -0.74509 & 81.75423 \\
\hline 115.9945 & 3.271434 & -0.73969 & 99.33686 & 118.9812 & 3.181362 & -1.2205 & 101.3744 & 98.10438 & 1.100217 & 85.75412 & 109.6445 & -4.8162 & 1.374137 & 89.07495 \\
\hline-28.9384 & 0.206909 & -2.44609 & -24.8736 & -25.3383 & -1.42588 & -1.80105 & -21.7768 & -22.4899 & -5.61027 & -20.3409 & -25.7069 & -1.14775 & -2.77461 & -21.3184 \\
\hline 4.19345 & -1.08323 & 0.652739 & 3.539916 & -1.51111 & 0.28042 & 0.166562 & -1.24924 & -3.73567 & 0.399421 & -3.2092 & -3.88784 & 0.04253 & -0.39825 & -3.20064 \\
\hline-42.86 & 1.330854 & 1.535906 & -36.4194 & -40.7404 & 1.722275 & 0.758025 & -34.4332 & -30.6539 & 3.969556 & -26.2457 & -37.5687 & 1.599404 & 3.434983 & -30.1986 \\
\hline-6.7136 & -2.2148 & -1.11537 & -5.98716 & -9.91081 & -3.66228 & -0.74061 & -8.80556 & -14.2523 & -4.94091 & -13.0669 & -12.7704 & 0.676798 & -1.42143 & -10.4687 \\
\hline-41.5125 & 0.306792 & -0.51436 & -35.4842 & -40.3198 & 1.028912 & -0.13212 & -34.191 & -31.5207 & 1.945027 & -27.2599 & -37.1636 & -1.05572 & -0.60637 & -30.4734 \\
\hline-47.679 & -0.59935 & -0.31203 & -40.8129 & -47.842 & -0.60272 & 0.115976 & -40.7218 & -40.5561 & -0.66957 & -35.4779 & -44.0019 & -0.82721 & -1.33055 & -36.0895 \\
\hline-55.3931 & 1.368574 & 1.692172 & -47.1165 & -51.2648 & 2.11881 & 1.049228 & -43.3273 & -39.6546 & 3.632535 & -34.1433 & -48.2093 & 0.402873 & 2.467174 & -39.08 \\
\hline
\end{tabular}

Table 6. Final Financial Competitiveness and Ranking of the PRD Cities

\begin{tabular}{|c|c|c|c|c|c|c|c|c|c|}
\hline & Guangzhou & Shenzhen & Zhuhai & Foshan & Huizhou & Dongguan & Zhongshan & Jiangmen & Zhaoqing \\
\hline $\begin{array}{l}\text { Final } \\
\text { score }\end{array}$ & 81.67282 & 93.88509 & 22.0774 & $\begin{array}{c}- \\
1.02979\end{array}$ & -31.8242 & -9.58207 & -31.8521 & -38.2755 & -40.9168 \\
\hline Ranking & 2 & 1 & 5 & 3 & 6 & 4 & 7 & 8 & 9 \\
\hline
\end{tabular}

\subsection{Financial Competitiveness of PRD Cities}

Table 6 shows that the final scores of Guangzhou and Shenzhen are higher than 0 , indicating that the financial competitiveness of these two cities is higher than the average financial competitiveness in the PRD. However, the final scores of the remaining cities are less than 0 , signifying that the financial competitiveness of these cities is lower than the average financial competitiveness in the PRD; moreover, the score of Foshan is closer to the average level than those of the other cities are. In particular, the final scores of Guangzhou and Shenzhen are considerably higher than those of the other cities, suggesting that Guangzhou and Shenzhen demonstrate considerably higher financial competitiveness compared with the other cities in the PRD; Shenzhen exhibits the highest financial competitiveness among the cities.

The financial industry in Guangzhou, the capital of Guangdong Province, is developing rapidly. Guangzhou has demonstrated a steady growth in economic strength because of the appropriate policies and decision-making of the central government as well as its strategic geographical location (adjacent to Hong Kong and Macao). In recent years, Guangzhou has expedited the development of the financial industry in several respects, 
including the establishment of financial functional areas, development of financial market platforms, development of financial headquarters, construction of capital markets, and implementation of reforms and innovations. The Chinese government has studied and introduced several preferential policies to support the financial industry and increase financial investment. Such preferential policies are a crucial and powerful driving force of the financial development of Guangzhou. In addition, the government organizes "the new Guangzhou new business opportunities" series seminar in which financial investment, capital market investment, and financial platforms constitute the major topic.

As the location of one of the mainland stock exchanges (Shenzhen Stock Exchange) and China's reform and opening up, Shenzhen's financial industry can be traced back several years. This financial industry exhibits the advantages of an effective policy, a favorable geographical location, and a developed financial market, and it is ranked in the top three among China's financial industries, after Shanghai and Beijing. The Shenzhen Municipal Government presented "Opinions on deepening financial reforms and innovations" in a 2014 document titled "Document No. 1." In this document, the government projected that before the year 2020, Shenzhen must be developed into a modern international financial center city with complete financial institutions, a multifunctional market, and an integrated, first-class business environment. Therefore, a WMC must be promptly constructed in this city.

Except Shenzhen and Guangzhou, the cities in the PRD are constantly in development. The development of the financial industries of Guangzhou and Shenzhen is also extended to several other cities. In particular, the financial competitiveness in Foshan increased from below average to above average in the studied 3 years. In the GuangzhouFoshan-Zhaoqing economic circle, these constituent cities cooperate vertically and horizontally. In addition, Nansha, Qianhai, and Hengqin are considered key development alliances. This regional cooperation in the PRD has ushered in new development opportunities.

Shenzhen and Guangzhou rank first and second, respectively, regarding financial competitiveness in the PRD. Therefore, these cities should be prioritized in developing the financial industry in the PRD into an integrated economy. Concurrently, the financial competitiveness of Guangzhou and Shenzhen should be enhanced to its ultimate level, and the financial competitiveness of the other cities in the PRD should be appropriately developed according to the actual situation and characteristics of each of these cities. Finally, maximum effort should be concentrated on developing financial innovation and an open platform in Nansha District in Guangzhou, Qianhai District in Shenzhen, and Hengqin District in Zhuhai. In particular, to ensure advantageous cooperation among the cities in the PRD, Hong Kong and Macao should help Guangdong to establish a competitive financial innovation region.

\section{Conclusion and Recommendations}

We design an urban financial competitiveness evaluation system to comprehensively and objectively determine the status of the financial industry and urban development potential in the PRD. This system can be used to thoroughly analyze the advantages and disadvantages of a city's financial development, which plays an increasingly essential role in enhancing a city's financial industry. According to the results of previous domestic and international studies on urban financial competitiveness in addition to the development status and characteristics of the financial industry in the PRD, we construct a system for evaluating WMCs in the PRD on the basis of three major indicators, namely city financial environment, urban financial scale, and urban benefits and deepening. The empirical results are summarized as follows: (1) Shenzhen and Guangzhou rank first and second, respectively, regarding financial competitiveness in the PRD region, and the financial competitiveness of both cities is considerably greater than that of the remaining cities. 
Consequently, Shenzhen and Guangzhou should be prioritized in establishing WMCs in the PRD. These cities should be strengthened to ensure that they provide a basis for the financial development of the other cities in the PRD. First, considerable effort should be concentrated on providing a suitable environment for financial organizations in all domains; this can be achieved by implementing policies that provide preferential conditions or protection for the establishment and development of financial companies and by developing information sharing platforms to enable financial companies to easily obtain information. Moreover, to provide the basis for the financial development of the other cities in the PRD, Shenzhen and Guangzhou should share their success stories with these cities; this can promote the financial and economic development of these cities, facilitating the construction of WMCs in the PRD. (2) Stock exchanges play a major role in the development of the financial industry in Shenzhen. Guangzhou should expedite the establishment of the Options Exchange to enable Guangzhou and Shenzhen to capitalize on their own advantages to guide the construction of WMCs in the PRD. This can strengthen the PRD Finance Circle and further develop the PRD financial industry into an integrated economy.

\section{Acknowledgements}

We are very grateful for financial support from Guangdong Universities Humanities and Social Science Key Research Base Project (No. 2012JDXM_0006), the National Natural Science Foundation of China (No. 71171086), the Fundamental Research Funds for the Central Universities SCUT (No. 2015ZZ058), and2015 Guangzhou Philosophy and Social Sciences 'Twelfth Five-Year Plan' Project (No. 15G10).

\section{References}

[1] R. Anderton and A. Dunnett, "Modelling the behaviour of export volumes of manufactures: An evaluation of the performance of different measures of international competitiveness", National Institute Economic Review, (1987), pp. 46-52.

[2] M. E. Porter, "The Competitive Advantage of Nations", Free Press, (1990).

[3] M. Oral and H. Chabchoub, "On the methodology of the world competitiveness report", European Journal of Operational Research, vol. 90, no. 3, (1996), pp. 514-535.

[4] M. Oral and H. Chabchoub, "An estimation model for replicating the rankings of the world competitiveness report", International Journal of Forecasting, vol. 13, (1997), pp. 527-537.

[5] H. C. Reed, "The preeminence of international financial centers", Praeger Publishers, (1981).

[6] D. R. Meyer, "The formation of a global financial center: London and its intermediaries", Cities in the World-system, (1991), p. 106.

[7] B. V. Christensen, "Switzerland's role as an international financial center", International monetary fund, (1986).

[8] H. C. Reed, "The Ascent of Tokyo as an International Financial Center", Journal of International Business Studies, vol. 11, no. 3, (1980), pp. 19-35.

[9] R. C. Bryant, "The evolution of Singapore as a financial center", Brookings Institution, (1986)

[10] Y. C. Jao, "Hong Kong as an International Financial Center: Evolution, Prospects and Policies", City University of Hong Kong Press, (1997).

[11] J. P. H. Poon, "Hierarchical Tendencies of Capital markets among international financial centers, Growth and change", vol. 34, no. 2, (2003), pp. 135-156.

[12] H. G. Johnson, "Panama as a Regional Financial Center: A Preliminary Analysis of Development Contribution, Economic Development and Cultural Change", vol. 24, no. 2, (1976), pp. 261-286.

[13] J. W. Wang, "Empirical Research on Regional Financial Development and Regional Economic Growth in China", Finance \& Trade Economics, vol. 10, (2005), p. 004.

[14] X. S. Yin, Y. F. He and H. S. Xu, "Analysis of Yangtze River Delta financial cluster situation and enhance the competitiveness", Shanghai Financial, vol. 8, (2003), pp. 42-44.

[15] D. W. Xiao, "Research of northeast urban financial competitiveness", Changchun: Northeast Normal University master's degree thesis, (2006).

[16] J. S. Zhang, L. Q. Yu and W. X. Xiong, "Index evaluation system of Chinese urban financial competitiveness", Opening Herald, vol. 4, (2008), pp.76-80.

[17] X. Z. Cheng and X. Y. Tang, "Evaluation and comparison of the financial competitiveness of western capital cities", Prices Monthly, vol. 2, (2009), pp. 63-65.

[18] M. Y. Fang, "Empirical Analysis of Financial radiation of Pearl River Delta cities", South Financial, vol. 


\section{7, (2009), pp. 65-68.}

[19] L. J. Zou, "The Investment performance evaluation model based on the Provincial Panel Data Finance Technology", Future and Development, vol. 1, (2013), pp. 26-29.

[20] L. Yue and B. Rao, "Design and evaluation method of comprehensive evaluation index system of urban development level”, Statistics and Decision, vol. 11, (2009), pp. 155-157.

[21] Y. B. Qi and L. L. Jiang, "Empirical study of financial center maturity assessment system", Shanghai Management Science, vol. 32, no. 1, (2010), pp. 38-41.

[22] L. F. Wu and S. F. Liu, "Panel data clustering method and application based on gray relational degree", Control and Decision, vol. 28, no. 7, (2013), pp. 1033-1036. 